period. After 2001, both RA comorbidity and mortality rates decreased annually by $-0.5 \%$ and $-4.8 \%$, respectively, with annual changes of $-4.4 \%$ to $-2 \%$ and from 2011- 2015, respectively. The overall mortality rate in RA patients after age adjustment was 2.5 -times $(95 \% \mathrm{Cl}: 2.52-2.65)$ higher than the general population between 1980- 2015 and 1.5-times (95\%Cl: 1.39-1.81) for the period 2011-2015. Conclusion: The annual comorbidity prevalence and mortality rates in WA have decreased significantly since 2001 reflecting improvements in the management of RA and comorbidity. Nonetheless, the mortality rate in RA patients in WA remains 1.5-times higher than their community counterparts suggesting that there is room to achieve further improvements.

REFERENCES:

[1] Meune C, Touze E, Trinquart L, Allanore Y (2009) Trends in cardiovascular mortality in patients with rheumatoid arthritis over 50 years: a systematic review and meta-analysis of cohort studies. Rheumatology (Oxford) 48:1309-1313. doi:10.1093/rheumatology/kep252

Acknowledgements: Khalid Almutairi was supported by an Australian Government Research Training Program PhD Scholarship at the University of Western Australia.

Disclosure of Interests: Khalid Almutairi: None declared, Johannes Nossent Speakers bureau: Janssen, David Preen: None declared, Helen Keen Speakers bureau: Pfizer Australia, Abbvie Australia, Charles Inderjeeth Speakers bureau: Eli Lilly.

DOI: 10.1136/annrheumdis-2021-eular.340

\section{OP0101 RHEUMATOID ARTHRITIS DISEASE ACTIVITY OVER TIME AND SUBSEQUENT CARDIOVASCULAR RISKS.}

K. Yoshida ${ }^{1}$, H. Guan ${ }^{1}$, S. Stryker ${ }^{2}$, E. Karis ${ }^{2}$, L. Harrold ${ }^{3}$, D. Solomon ${ }^{1}$. ${ }^{1}$ Brigham and Women's Hospital, Division of Rheumatology, Inflammation, and Immunity, Boston, United States of America; ${ }^{2}$ Amgen, Inc., Thousand Oaks, United States of America; ${ }^{3}$ Corrona, LLC., Waltham, MA, United States of America

Background: Rheumatoid arthritis (RA) patients have an increased risk of cardiovascular (CV) events not fully explained by traditional CV risk factors. The relationship between fluctuating inflammation due to RA disease activity and CV events is of interest.

Objectives: To examine the influence of time-varying disease activity on the subsequent risks of $\mathrm{CV}$ disease.

Methods: We followed patients from a large US registry of clinically diagnosed RA patients, starting at their first visit with a Clinical Disease Activity Index (CDAl) through the end of follow-up or first CV event. Exposure of interest was disease activity measured by categorical CDAI (high, moderate, low, and remission) averaged within each 6-month window. The outcome of interest was major adverse CV events (MACE) defined as non-fatal myocardial infarction, non-fatal stroke (excluding transient ischemic attacks), and CV death. For baseline confounders we considered age, gender, race, disease duration, Health Assessment Questionnaire, hypertension, diabetes, hyperlipidemia, family history of premature $(a g e<50)$ CV events, and RF/ACPA seropositivity. For time-varying variables we considered tumor necrosis factor inhibitor (TNFi), non-TNFi biologic, methotrexate, oral glucocorticoid, non-steroidal anti-inflammatory drugs, statin, and aspirin use. We used the marginal structural model (MSM) framework to examine the impact of CDAI at each 6-month interval on MACE. We estimated time-varying hazard ratios (HRs) comparing high CDAI during follow-up to CDAI remission. Several predicted survival curves were constructed under different hypothetical CDAl scenarios, such as early and late transition to CDAI remission.

Results: 40,721 patients were eligible for our analyses. $77 \%$ were female and $84 \%$ were Caucasian. The mean age was 58 (SD 13) years with mean disease duration of 8.8 (median 5) years. Mean CDAl at their first registry visit was 14 (SD 13; remission 19\%, low 31\%, moderate $28 \%$, and high $22 \%$ ). Other baseline characteristics include: $41 \%$ current/former smokers, 31.5\% with hypertension, $8.6 \%$ with diabetes, $18 \%$ with hyperlipidemia, and $52 \%$ seropositive. The average follow-up duration after baseline was 4.4 (median 3.3; max. 17.6) years. The crude event count of MACE was 1,050 events / 180,402 person-years.

In the MSM analysis, the average HRs, assuming a constant HR, were 1.31 $[0.90,1.90]$ for low, $1.46[1.01,2.10]$ for moderate, and $1.43[0.89,2.31]$ for high CDAl disease activity categories during each 6-month interval. When approximating time-varying HR with linear trends, the highest estimates during the first 6 months of follow up were 1.61 [0.93, 2.77] for low CDAI, 1.97 [1.13, 3.43] for moderate CDAI, and 2.11 [1.13, 3.96] for high CDAI. These HRs gradually diminished during the follow up (Table). When we constructed hypothetical survival curves with transition to CDAI remission at different time points, earlier transition to CDAI remission was related to better event-free survival (Figure).
Table 1. Time-varying hazard ratio estimates [ $95 \%$ confidence intervals] by duration in study

\begin{tabular}{lcccc}
\hline \multicolumn{5}{c}{ Disease activity measured by CDAl } \\
\hline Year & Remission & Low & Moderate & High \\
\hline 0.5 & $1.00[\mathrm{ref}]$ & $1.61[0.93,2.77]$ & $1.97[1.13,3.43]$ & $2.11[1.13,3.96]$ \\
1 & $1.00[\mathrm{ref}]$ & $1.54[0.97,2.44]$ & $1.85[1.17,2.93]$ & $1.94[1.13,3.31]$ \\
2 & $1.00[\mathrm{ref}]$ & $1.42[1.00,2.01]$ & $1.63[1.16,2.29]$ & $1.62[1.04,2.54]$ \\
3 & $1.00[\mathrm{ref}]$ & $1.31[0.90,1.90]$ & $1.43[0.97,2.11]$ & $1.36[0.80,2.31]$ \\
4 & $1.00[\mathrm{ref}]$ & $1.20[0.72,2.02]$ & $1.26[0.72,2.21]$ & $1.14[0.55,2.36]$ \\
5 & $1.00[\mathrm{ref}]$ & $1.11[0.54,2.26]$ & $1.11[0.51,2.42]$ & $0.96[0.36,2.53]$
\end{tabular}

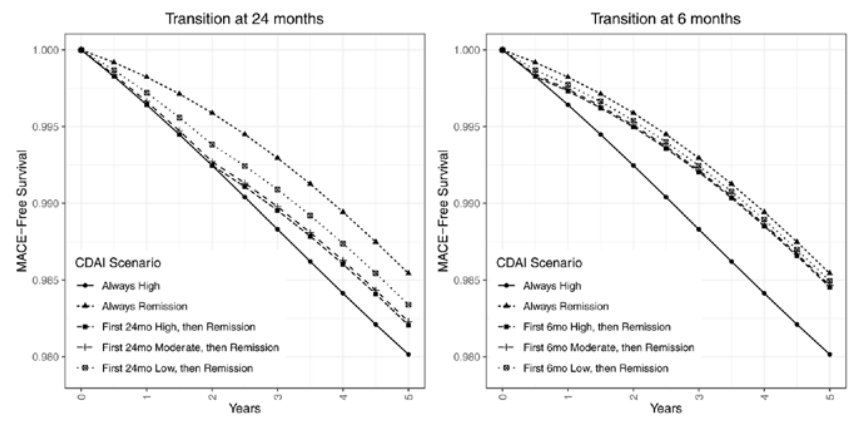

Figure 1. MACE-free survival curves under hypothetical CDAl scenarios

Conclusion: High and moderate CDAI were associated with higher hazard of MACE during the earlier period of follow-up, but the increased hazard diminished over time. In hypothetical senarios, earlier transition to CDAI remission would improve MACE free-survival.

Acknowledgements: This study was sponsored by Corrona, LLC. Corrona is supported through contracted subscriptions with multiple pharmaceutical companies. The analysis was financially supported by Amgen Inc.

Disclosure of Interests: Kazuki Yoshida Consultant of: OM1, Inc., Grant/ research support from: Corrona, LLC., Hongshu Guan: None declared, Scot Stryker Shareholder of: Amgen, Inc., Employee of: Amgen, Inc., Elaine Karis Shareholder of: Amgen, Inc., Employee of: Amgen, Inc., Leslie Harrold Consultant of: AbbVie, Bristol-Myers Squibb, Genentech/Roche, Grant/research support from: Pfizer, Daniel Solomon Grant/research support from: DHS receives salary support from research contracts through Brigham and Women's Hospital with Abbvie, Amgen, Corrona, Genentech and Janssen.

DOI: 10.1136/annrheumdis-2021-eular.28

\section{OP0102 DECLINE IN EXCESS RISK OF HEART FAILURE IN PATIENTS WITH RHEUMATOID ARTHRITIS IN RECENT YEARS}

E. Myasoedova ${ }^{1,2}$, J. M. Davis III ${ }^{1}$, S. Achenbach ${ }^{3}$, K. Wright ${ }^{1}$, R. Kurmann ${ }^{4,5}$, R. Mankad ${ }^{4}$, V. Roger ${ }^{4}$, C. S. Crowson ${ }^{3} .{ }^{1}$ Mayo Clinic, Rheumatology, Rochester, MN, United States of America; ${ }^{2}$ Mayo Clinic, Quantitative Health Sciences, Epidemiology, Rochester, United States of America; ${ }^{3}$ Mayo Clinic, Quantitative Health Sciences, Biomedical Statistics and Informatics, Rochester, United States of America; ${ }^{4}$ Mayo Clinic, Cardiovascular Disease, Rochester, United States of America; ${ }^{5}$ Luzerner Kantonsspital, Department of Cardiology, Heart Center, Lucerne, Switzerland

Background: Heart failure (HF) is one of the most common cardiovascula conditions in patients with rheumatoid arthritis (RA). Previous studies showed a 2-fold excess risk of HF in RA versus the general population (1). Whether this has changed over time is not known. Longitudinal studies on trends in occurrence of $\mathrm{HF}$ in RA patients over time, and studies comparing trends in HF in RA versus the general population are lacking.

Objectives: 1) To assess trends in incidence of HF in patients with incident RA in 1980-2009; and 2) To compare incidence of HF in RA patients and population-based comparators without RA with RA incidence/ index date in 1980-2009.

Methods: The study population comprised Olmsted County, Minnesota residents with incident RA (age $\geq 18$ years, 1987 ACR criteria met in 1980-2009) and non-RA subjects from the same underlying population with similar age, sex and calendar year of index. All subjects were followed until death, migration, or 04/30/2019 Incident HF was defined using Framingham criteria. Patients with HF prior to RA incidence/index date were excluded. Cox proportional hazards models were used 